\title{
Recent Progress on the Fabrication and Properties of Silver Nanowire-Based Transparent Electrodes
}

\author{
Renyun Zhang ${ }^{1, *}$ (1) and Magnus Engholm ${ }^{2}$ (D) \\ 1 Department of Natural Sciences, Mid Sweden University, SE-85170 Sundsvall, Sweden \\ 2 Department of Electronics Design, Mid Sweden University, SE-85170 Sundsvall, Sweden; \\ magnus.engholm@miun.se \\ * Correspondence: renyun.zhang@miun.se; Tel.: +46-10-1428284
}

Received: 31 July 2018; Accepted: 14 August 2018; Published: 18 August 2018

\begin{abstract}
Transparent electrodes (TEs) made of metallic nanowires, such as $\mathrm{Ag}, \mathrm{Au}, \mathrm{Cu}$, and $\mathrm{Ni}$, are attracting increasing attention for several reasons: (1) they can act as a substitute for tin oxide-based TEs such as indium-tin oxide (ITO) and fluorine-doped tin oxide (FTO); (2) various methods exist for fabricating such TEs such as filtration, spraying, and Meyer bar coating; (3) greater compatibility with different substrates can be achieved due to the variety of fabrication methods; and (4) extra functions in addition to serving as electrodes, such as catalytic abilities, can be obtained due to the metals of which the TEs are composed. There are a large number of applications for TEs, ranging from electronics and sensors to biomedical devices. This short review is a summary of recent progress, mainly over the past five years, on silver nanowire-based TEs. The focus of the review is on theory development, mechanical, chemical, and thermal stability as well as optical properties. The many applications of TEs are outside the scope of this review.
\end{abstract}

Keywords: transparent electrodes; silver nanowires; mechanical stabilities; chemical stabilities; thermal stabilities; optical properties

\section{Introduction}

Transparent electrodes (TEs) are essential components in many optoelectronic applications such as solar cells, touch screen displays, and film heaters [1]. The materials used for making these electrodes are mainly transparent conductive oxides (TCOs) such as indium-tin oxide (ITO), fluorine-doped tin oxide (FTO), and doped zinc oxide. However, the low availability of these elements and the high demands imposed by the fabrication conditions lead to high prices for these TEs. In addition, the brittleness of the materials limits their application in new types of flexible electronics such as wearable sensors.

Therefore, new materials, such as conductive polymers, carbon nanotubes, graphene, ultra-thin metal films, and metallic nanowires, have been adopted for fabricating TEs. Despite the wide choice of materials, few of these can fulfill the requirements of industrial production (transmittance $>90 \%$ and sheet resistance $<100 \Omega$ /sq) [2]. Research has shown that metallic nanowires can fulfill these requirements. Thus, increasing efforts have been made in this area, such as developing new methods for synthesizing nanowires, new deposition methods, and new post-deposition procedures.

Ag nanowires are the most studied material for making metallic nanowire-based TEs. One reason is that the methods for synthesizing silver nanowires are relatively simple and the chemical stability of silver is better than other metals such as copper. When compared to other nanowires such as carbon nanotubes, the advantage of silver nanowires is that they can create networks having better electrical conductivity. The most common route is to synthesize Ag nanowires followed by deposition 
on different substrates using methods such as electrostatic spraying [3,4], doctor blading [5], electroless deposition [6], Meyer bar coating [7], ink jet printing [8], and spin coating [9].

Results from studies before 2013 showed that bare Ag nanowires can easily be deposited on different substrates by using the techniques mentioned above, and the length to diameter ratio of the nanowire determines whether the nanowires have the potential to achieve the requirements for industrial production (transmittance $>90 \%$ and sheet resistance $<100 \Omega / \mathrm{sq}$ ) [2].

Recent trends have been to enhance the electrical stability, flexibility, and chemical and thermal stabilities, to tune the optical properties and to apply these TEs in different optoelectronic applications. Recent reviews, see e.g., Sannicolo et al. or Xue et al. $[10,11]$ have summarized the advantages of nanowire-based TEs and their applications in flexible electronics and optoelectronics.

This short review summarizes the main advances in silver nanowire-based TEs that have been made in the past five years. The review focuses on theory development, mechanical and chemical stability, and tuning of the optical properties.

\section{Theoretical Approaches}

\subsection{Transparency and Conductivity}

Transparency and conductivity are the two most important parameters for characterizing TEs. For a bulk-like film such as ITO, the transparency, which is usually quantitatively expressed as the transmittance $(T)$, is related to the sheet resistance $\left(R_{S}\right)$ of the film [12]:

$$
T=e^{-\alpha / \sigma_{\mathrm{DC}, \mathrm{B}} R_{\mathrm{S}}},
$$

where $\alpha$ is the absorption coefficient and $\sigma_{\mathrm{DC}, \mathrm{B}}$ is the bulk DC conductivity of the film.

Metallic nanowire-based TEs have different mechanisms for their transmittance, based on the free space [12] among the nanowires instead of the absorption coefficient of the material. This means that the density of the nanowires determines the transparency of the TEs. Depending on the density of the nanowires, the transparent films, represented by the relation between the transmittance and the sheet resistance, are found to be either bulk-like or percolative.

In the bulk-like regime, the transmittance can be expressed as:

$$
T=\left(1+\frac{Z_{0}}{2} \sigma_{\mathrm{Op}} t\right)^{-2}
$$

where $\sigma_{\mathrm{Op}}$ is the optical conductivity $\left(\sigma_{\mathrm{Op}} \approx \alpha / Z_{0}\right)$ and $Z_{0}$ is the impedance of free space (377 $\Omega$ ) [13]. In percolation theory [14], the conductivity $\left(\sigma_{\mathrm{DC}}\right)$ of the nanowire film is non-linearly related to the difference between the density of the nanowires per unit area, $n$, and the percolation threshold, $n_{c}$ :

$$
\sigma_{\mathrm{DC}} \propto\left(n-n_{c}\right)^{m}
$$

$n_{c}$, also called the percolation threshold, ref. [14] is the value at which the network has a percolation probability of $1 / 2$, and the exponent $m$ has been found, by Monte Carlo simulation, to be 4/3 [15]. The value of $n_{\mathcal{c}}$ is determined by the length of the nanowires $\left(L_{\mathrm{NW}}\right)$ using the equation [14]:

$$
n_{c}=5.63726 / L_{\mathrm{NW}}{ }^{2},
$$

By combining Equations (2) and (3), one can predict the relation between the transmittance and the sheet resistance using an equation suggested by Grüner and co-workers [16,17]:

$$
T=\left(1+\frac{Z_{0}}{2 R_{s}} \frac{\sigma_{\mathrm{Op}}}{\sigma_{\mathrm{DC}}}\right)^{-2}
$$


The experimental data from different materials with transmittance values from 0 to critical values, depending on the structure of the materials, can be fit using Equation (5) (Figure 1). Beyond the critical values, the data deviate from the fitting curves, and percolation theory should be applied.

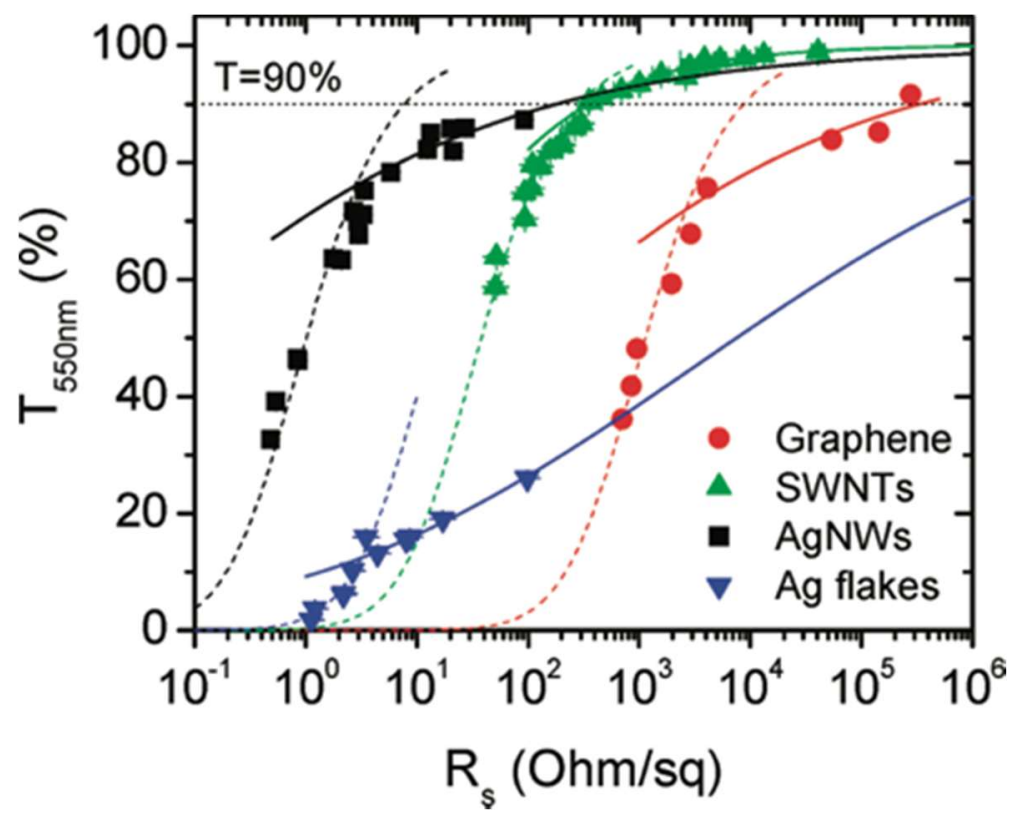

Figure 1. Transmittance $(550 \mathrm{~nm})$ plotted as a function of sheet resistance for thin films prepared from four nanostructured materials: graphene, single-walled carbon nanotubes, silver nanowires, and silver flakes. The dashed lines represent fits to the bulk regime using Equation (5), while the solid lines represent fits to the percolative regime using Equation (9). Reprinted from [12], with permission from American Chemical Society, 2010.

The conductivity, $\sigma_{\mathrm{DC}}$ of a nanowire network film can also be expressed using the thickness of the films [15]:

$$
\sigma_{\mathrm{DC}} \propto\left(t-t_{\mathrm{C}}\right)^{n}
$$

where $t_{\mathrm{c}}$ is the threshold thickness and $n$ is the percolation exponent. For a network with a conductivity high enough for industrial production, $t$ is always greater than $t_{\mathrm{c}}$ [12]. Based on this, Coleman and co-workers [12] have further defined the relation between $\sigma_{\mathrm{DC}}$ and $\sigma_{\mathrm{DC}, \mathrm{B}}$ using the equation:

$$
\sigma_{\mathrm{DC}}=\sigma_{\mathrm{DC}, \mathrm{B}}\left(\frac{t}{t_{\min }}\right)^{n},
$$

where $t_{\min }$ is the thickness of the nanowire network film that has $\sigma_{\mathrm{DC}}$ equal to $\sigma_{\mathrm{DC}, \mathrm{B}}$, usually 2.33 times the diameter of the nanowires.

Coleman et al. [12] have further used $n$ to define a percolation Figure of Merit $\Pi$, that defines the relation between the transmittance $T$ and the sheet resistance $R_{S}$ of a TE:

$$
\begin{aligned}
& \Pi=2\left[\frac{\frac{\sigma_{\mathrm{DC}, \mathrm{B}}}{\sigma_{\mathrm{Op}}}}{\left(Z_{0} t_{\min } \sigma_{\mathrm{Op}}\right)^{n}}\right]^{\frac{1}{n+1}}, \\
& T=\left[1+\frac{1}{\Pi}\left(\frac{Z_{0}}{R_{\mathrm{s}}}\right)^{\frac{1}{n+1}}\right]^{-2} .
\end{aligned}
$$


By fitting the experimental data (Figure 1) with Equation (9), it is easy to get the values of $\Pi$ and $n$. $\Pi$ is a dimensionless number that reflect the values of the sheet resistance and the transmittance. The value of $n$ reflects the junction resistance in the nanowire networks, where a small value indicates less junction resistance.

The fitting results in Figure 1 indicate that Equations (5) and (9) fit very well at the regime where it applies. Such fitting is of great importance to predict the possibility of the method to produce TEs that meet the requirements.

\subsection{Transmission and Film Parameters}

Mutiso and co-workers [18] developed another method to simulate nanowire-based networks. In their work, the sheet resistance is calculated based on the effective contact resistance $\left(R_{\mathrm{c} \_ \text {effective }}\right)$ between the nanowires. They use the area fraction $(A F)$ to define the density of the nanowires and, subsequently, the transmittance using the empirical equation [18]:

$$
T \%=100-a_{1} A F
$$

where $a_{1}$ is a fitting parameter that accounts for the diameter and wavelength-dependent optical properties of the nanowires.

A plot of the transmittance and the sheet resistance shows a perfect fit using this method in both the bulk-like and percolative regimes. However, the ratio between the lengths and diameters must be given in order to perform the simulation.

Recently, Khanarian and co-workers [19] further developed the Mie light scattering theory of spheres and applied it to nanowires to predict both the transmission and the haze.

The transmission of a Ag-nanowire film with thickness $d$ is given by:

$$
T=e^{-n_{v} C_{\mathrm{ext}} d}
$$

where $C_{\text {ext }}$ is the extinction coefficient of the nanowires given by Mie theory [20] and $n_{v}$ is the number of nanowires per volume, which is related to the volume fraction $\Phi_{v}$, the diameter $D$, and the length $L$ by the equation below.

$$
n_{v}=\frac{\Phi_{v}}{L \pi\left(\frac{D^{2}}{4}\right)},
$$

For TEs made of Ag nanowires with a thickness less than $100 \mathrm{~nm}$, the transmission has been found to be better represented by:

$$
T=e^{-n_{s} C_{\mathrm{ext}}}
$$

where $n_{s}$ is the number of nanowires per unit area.

This approach predicts the relationship between the transmittance of the TEs and the surface fraction $\left(\Phi_{\mathrm{S}}\right)$ of silver nanowires with respect to different diameters since $n_{S}$ can be presented as:

$$
n_{s}=\frac{\Phi_{\mathrm{s}}}{D L}
$$

\subsection{Haze}

Haze refers to the amount of light that is subject to wide scattering when passing through nanowire films. It is an important parameter for describing the optical properties of nanowire-based TEs. However, theoretical approaches that predict haze are limited.

Khanarian and co-workers [19] extended the derivation provided by Willmouth [21] to derive an expression for haze in Ag nanowire films. The geometry of the scattered light passing through a Ag nanowire film is schematically presented in Figure 2. They further assumed that the Fresnel 
transmission terms [21] could be approximated by their average values at each optical interface. Then, an expression to predict the haze for nanowires was derived as follows:

$$
H=\frac{F_{12} F_{23} \frac{C_{2.5}^{90}}{C_{\mathrm{ext}}}\left(1-e^{-\Phi_{\mathrm{s}} Q_{\mathrm{ext}}}\right)}{F_{12} F_{23} F_{31} e^{-\Phi_{\mathrm{s}} Q_{\mathrm{ext}}}+F_{12} F_{23} \frac{C_{0}^{90}}{C_{\mathrm{ext}}}\left(1-e^{-\Phi_{\mathrm{s}} Q_{\mathrm{ext}}}\right)}
$$

where $F_{i j}$ are the Fresnel transmission terms, $Q_{\text {ext }}$ is the scattering efficiency, $C_{m}^{n}$ is the scattering efficiency between angles $m$ and $n$, and $\Phi_{\mathrm{s}}$ is the surface fraction of the nanowires.

The haze has a linear relationship with $\Phi_{\mathrm{S}}$ (Figure 3) and increases significantly with the diameters of the silver nanowires. Such a phenomenon has been proved experimentally, which also agrees with Equation (15).

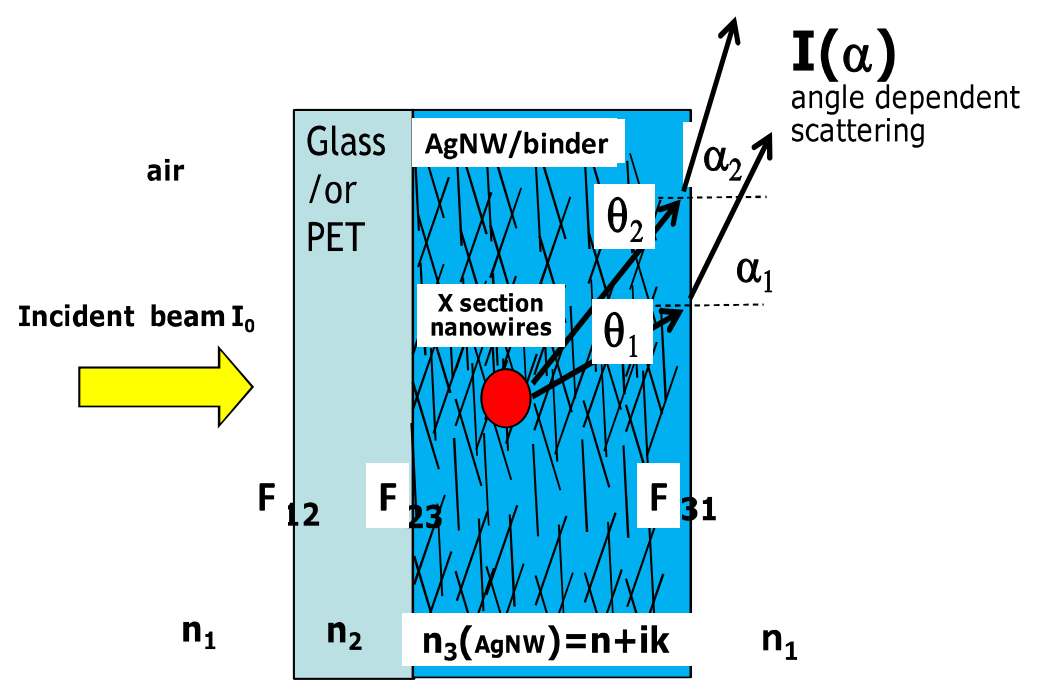

Figure 2. Scattering geometry of nanowires in films. Reprinted from [19], with the permission from AIP Publishing, 2013.

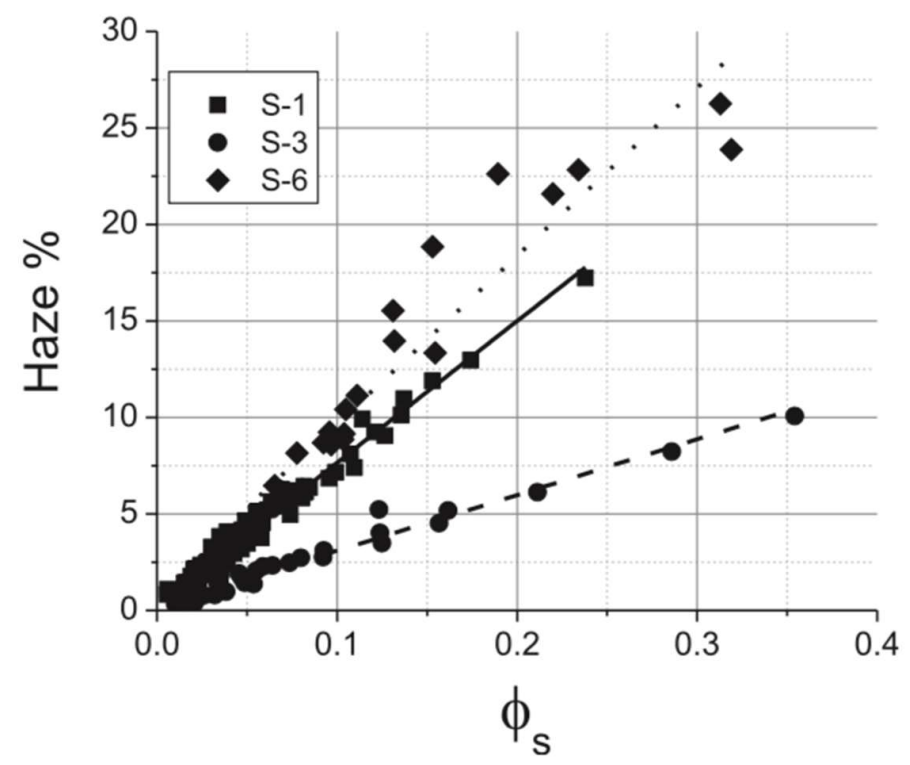

Figure 3. Optical haze versus silver area coverage /s for nanowires S-1 (100 nm), S-3 (56 nm), and S-6 $(153 \mathrm{~nm})$. Calculated curves are shown as ( , S-1), (- . - , S-3) and ( S-6). Reprinted from [19], with permission from AIP Publishing, 2013. 
It follows from Figure 3 that the haze is strongly dependent on the diameter of the Ag nanowires. Hence, for applications that require a low haze (e.g. displays, $H<1 \%$ ), it is found possible only for diameters less than $\sim 50 \mathrm{~nm}$.

Preston et al. [22] performed simulations and experiments on Ag nanowires and also came to the same conclusion. TEs with smaller Ag nanowire diameters have a lower haze and exhibit a better performance.

\section{Experimental Approaches}

\subsection{Electrical Stability}

Electrical stability [23] is one of the most important factors that needs to be considered to evaluate a silver nanowire based TE. It has been reported that silver nanowire networks break down due to electrical stress. Such a phenomenon could be due to electromigration [24] or elevated temperature [25] caused by Joule heating [26,27]. The joule heating occurs at the contact points of the silver nanowires, where a high contact resistance exists [28]. High current concentrates at the junction [27], leading to high current density with resulting Joule heating. The local temperature at the junction caused by Joule heating could reach $300{ }^{\circ} \mathrm{C}$ which leads to the melting of silver due to Plateau-Rayleigh instability [29]. The temperature could even go high enough to evaporate the silver [30]. Electromigration of silver happens when the nanowires suffer high current density. Under such a condition, the vacancies in the nanowires can sweep from anode to cathode or from cathode to anode [24], which creates a vacancy concentration gradient that results in a stress gradient. When the local stress gradient reaches a certain point, it will undergo an avalanche-like break down.

Attempts to increase the electrical stability of silver nanowire TEs include chemical treatment [31], electrical welding [32], laser sintering [33] etc. All these methods aim to reduce the resistance at junctions, which will reduce the local current density and thus reduce the Joule effect. However, such processed TEs have been shown not to fulfill the requirements for devices such as solar cells, as failure of the TEs have been observed under typical operational currents of solar cells [25].

An alternative way to increase the electrical stability is to coat the TEs with a thin layer of other materials such as $\mathrm{ZnO}$ [26] and poly(3,4-ethylene dioxythiophene):poly(styrene sulfonate) (PEDOT:PSS) [34]. The coating of such materials could delay the atomic surface diffusion of silver, since the atoms must diffuse through the coating layers before the deterioration of the junction can begin to occur [26].

\subsection{Mechanical Stability}

\subsubsection{Flexibility}

Flexibility is a crucial factor for TEs, as it is of great importance for their application in soft electronics, e.g., as wearable sensors. Flexibility is a factor that combines the mechanical and electrical stability of a TE and is usually characterized by plotting the electrical conductivity versus the cycles of mechanical bending. Several protocols have been developed for enhancing the mechanical flexibility of TEs, such as welding or the deposition of extra material.

Welding is one of the more effective ways to enhance the flexibility of TEs while retaining their electrical properties. The welding procedure improves the contacts between the nanowires so that the nanowire network can withstand higher mechanical stress. Thermal annealing, light irradiation, mechanical pressing, plasma treatment, extra coating, cold welding, and chemical treatment are methods that have been used for welding Ag nanowires.

Hwang and co-workers demonstrated the welding of $\mathrm{Ag}$ nanowires by post-annealing at $180{ }^{\circ} \mathrm{C}$ for $25 \mathrm{~min}$ [4], thereby forming fused-in junctions among the nanowires. This welding procedure can significantly enhance the flexibility of TEs, while retaining their electrical resistance after 500,000 cycles with a strain of $1 \%$. 
The welding of Ag nanowires with intense light is also an effective method for enhancing the flexibility of TEs. Kou et al. [1] reported the welding of Ag nanowires using simulated sunlight $\left(0.1 \mathrm{~W} / \mathrm{cm}^{2}\right)$. The welded TEs were shown to achieve the same flexibility as those welded at $200{ }^{\circ} \mathrm{C}$. A $1.8 \mathrm{~cm} \times 1.8 \mathrm{~cm}$ sized TE was found to maintain its electrical resistance after 500 cycles of bending to a minimum radius of curvature of $0.15 \mathrm{~cm}$. In addition to simulated sunlight, flashlight irradiation has also been used to weld Ag nanowires. Li et al. [35] used flashlight irradiation with an energy of $4.6 \mathrm{~J} / \mathrm{cm}^{2}$ per pulse to weld Ag nanowires on paper substrates. Hwan and co-workers [36] used a higher power density of $10.3 \mathrm{~J} / \mathrm{cm}^{2}$ to weld Ag nanowires with an average diameter of $35 \mathrm{~nm}$. High power lamps have also been used to weld Ag nanowires [37], where 10 to 120 seconds of irradiation under a tungsten-halogen lamp with a power density of $30 \mathrm{~W} / \mathrm{cm}^{2}$ can weld the junctions between the nanowires.

Plasma treatment has also been found to cause the welding of Ag nanowires. Zhu and co-workers [38] treated Ag nanowire films with $75 \mathrm{~W}$ room-temperature plasma at room temperature. The treated film maintained its electrical resistance after 10,000 bending cycles at a frequency of $2 \mathrm{~Hz}$.

Welding can also be done by post-deposition of $50 \mathrm{~nm}$ fluorine-doped $\mathrm{ZnO}$ (FZO) using a laser deposition method [9]. Using this method, no change in electrical resistance was observed after 1000 bending cycles, although the strain of the bending was not reported. Cheong et al. [39] welded Ag nanowires by depositing $30 \mathrm{~nm}$ and $50 \mathrm{~nm}$ indium tin oxide (ITO) using a DC magnetron sputtering system. The welded films maintained their electrical resistance during 10,000 bending cycles.

Capillary-force-induced cold welding [40] is a new method to create self-limited welding of the wire-wire junctions. These processes can be performed simply by applying moisture to the $\mathrm{Ag}$ nanowire films. However, this cold welding has not been fully studied, and the electrical resistance decreased at a bending radius of $1.5 \mathrm{~mm}$.

Chemical methods have also been reported to weld Ag nanowire films [31]. These methods are used for the deposition of Ag atoms at the junctions of the nanowires (Figure 4) because of the high local chemical potential of the concave surface [41]. The process can be easily performed by dipping the films in silver-containing solutions such as silver-ammonia [42].

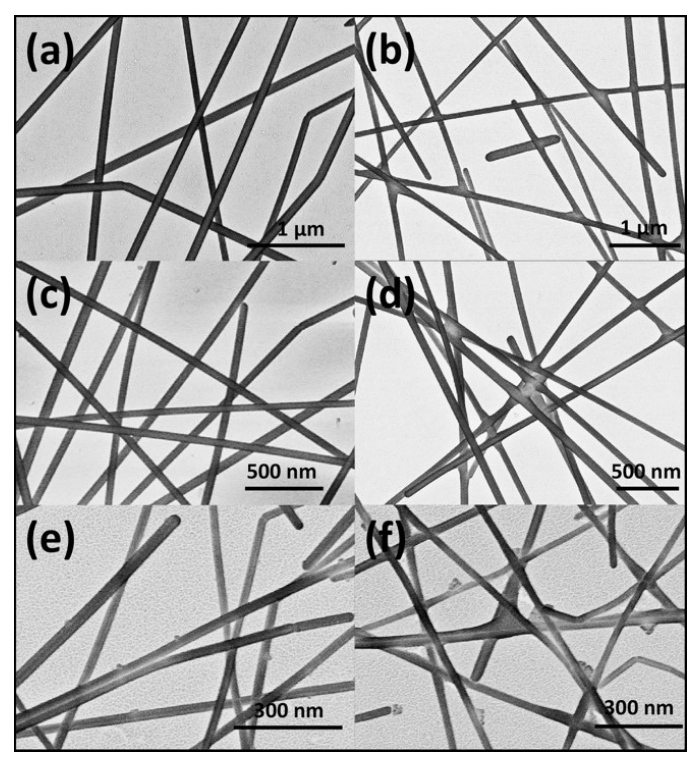

Figure 4. Scanning electron microscopy (SEM) images of transparent electrodes fabricated from $(\mathbf{a}, \mathbf{b})$ $100 \mathrm{~nm},(\mathbf{c}, \mathbf{d}) 60 \mathrm{~nm}$, and (e,f) $20 \mathrm{~nm}$ silver nanowires before and after chemical treatment. Reprinted from [31], with permission from John Wiley \& Sons, Inc., 2015.

\subsubsection{Adhesion}

Adhesion is another important parameter for the mechanical stability of TEs. The Ag nanowire films are not self-supporting, and thus, supporting substrates are required to hold the films. However, 
bare Ag nanowire films do not adhere well to most substrates, and additional procedures are required to enhance the adhesion.

There are two general routes for enhancing the adhesion between Ag nanowires and substrates. The first one directly increases the adhesion by using extra processes; the second one requires the addition of other materials.

Spontaneous heating of the Ag nanowires and the substrate can lead to stronger contact between the nanowires and the substrate, resulting in stronger adhesion. Lee and co-workers [43] laminated Ag nanowires on a polyethylene terephthalate (PET) substrate at $120^{\circ} \mathrm{C}$ to enhance the adhesion. Alternatively, other research groups used intense-pulse-light (IPL) to increase the adhesion between the nanowires and a substrate $[44,45]$. The IPL method can heat the nanowires and the substrate to a high temperature for a short period, thus increasing the contact between the materials.

In addition to heating, forces added to the films can increase the adhesion. A strong conformal pressure applied to the Ag nanowires can improve their adhesion to PET [46]. Liu and co-workers [31] noted that the capillary force produced by moisture on a Ag nanowire film can pull the nanowires to the substrate.

Although the methods mentioned above have been shown to increase the adhesion, they are less popular than those assisted by extra coating or by compositing the nanowire with substrate materials.

The coating of an extra layer, such as $\mathrm{ZnO}$ [47], aluminum-doped $\mathrm{ZnO}$ (AZO) [48] or $\mathrm{TiO}_{2}$ [49], by either atomic layer deposition (ALD) or sol-gel methods was found to significantly increase the adhesion. Graphene was also observed to increase the adhesion of Ag nanowires to a polyester yarn surface [50]. This is due to the existence of a large van der Waals force between graphene and the polyester (Figure 5), which helps to bind the Ag nanowires.
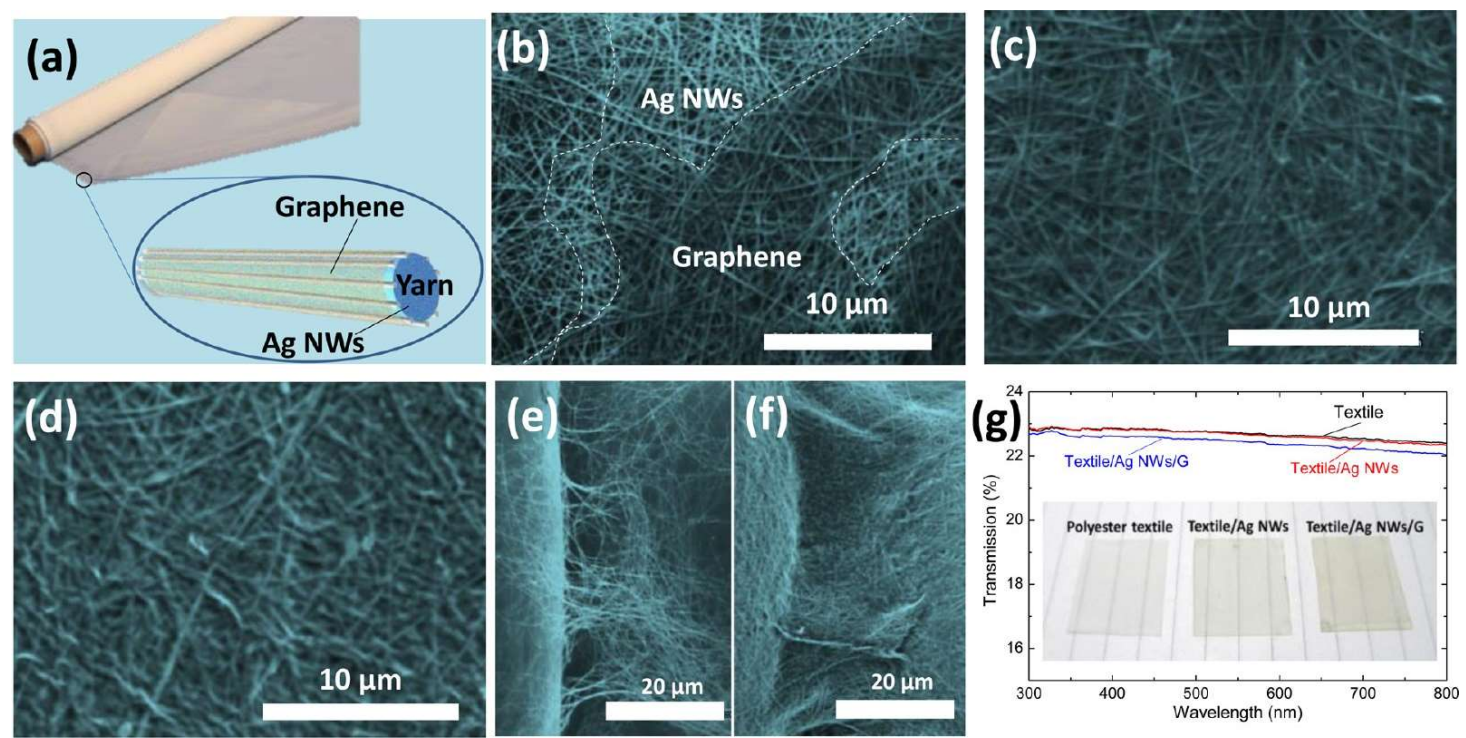

Figure 5. (a) Schematic diagram of an e-textile with a polyester/Ag nanowire (NW)/graphene core-shell structure. (b-d) SEM images of polyester/Ag NW/graphene samples with different numbers of graphene-coating cycles: (b) one cycle, (c) two cycles, and (d) three cycles. SEM images of the fiber cross-linked regions (e) before graphene coating and (f) after graphene coating. (g) Visible-light transmittance of the textile, the textile/Ag NW, and the textile/Ag NW/graphene samples; the insets are photographs. Reprinted from [50], with permission from American Chemical Society, 2016.

Compositing Ag nanowires with substrate polymers is another way to increase the adhesion. Nam and co-workers [51] embedded Ag nanowires in Norland Optical Adhesive (NOA) 63 to obtain strong adhesion. Other materials, such as chitosan [52], alginate [53], and polyvinyl alcohol [54], have also been composited with Ag nanowires, resulting in improved adhesion. 


\subsubsection{Stretchability}

Stretchability is specifically required for Ag nanowire TEs that need to withstand tensile, compressive and shear forces. To meet this requirement, both the Ag nanowire film and the substrate should be stretchable.

Hydroxylated polydimethylsiloxane (PDMS) [55-57] and polyurethane urea (PUU) [58] are two of the most commonly used substrate materials for stretchable TEs due to their excellent elasticity. In addition, poly(urethane acrylate) (PUA) [59] and polyimide [44] have also been used for supporting Ag nanowire layers. There are two main routes for depositing Ag nanowires on these substrates. One is to prepare the Ag nanowire film first and to then transfer it onto the substrate [55-57]; the other is to fabricate the Ag nanowire-polymer composite first and to then form a film of the composite [59].

The elasticity of the Ag nanowire films is the core of the stretchable TEs and determines the performance of the TEs. Since the Ag nanowires themselves are not elastic, structural designs are needed to ensure the electrical properties of the film under strain.

A random network of Ag nanowires can lead to increased electrical resistance when multiple cycles of mechanical strain are applied [59]. However, if the Ag nanowires are pre-strained to form a wrinkled structured film (Figure 6), the stretchability of the TEs is significantly enhanced [56]. Another protocol, reported by Kim and co-workers [55], is to make Ag TEs with wavy structured Ag nanowires. This was done by compressing the floating Ag nanowire film before it was transferred onto PDMS.

a

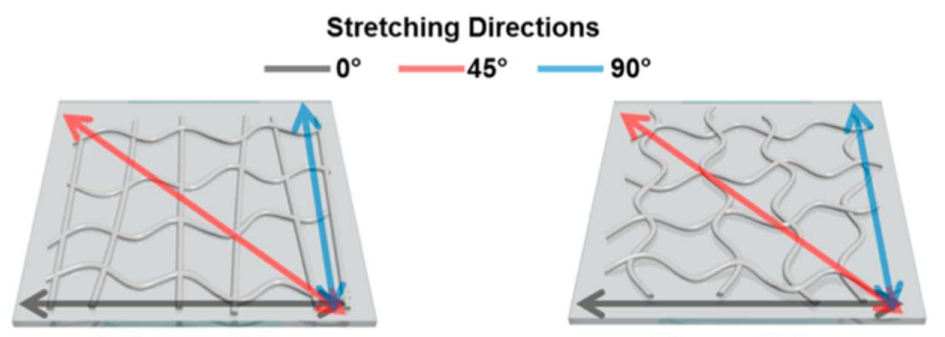

Uni-wavy NWs
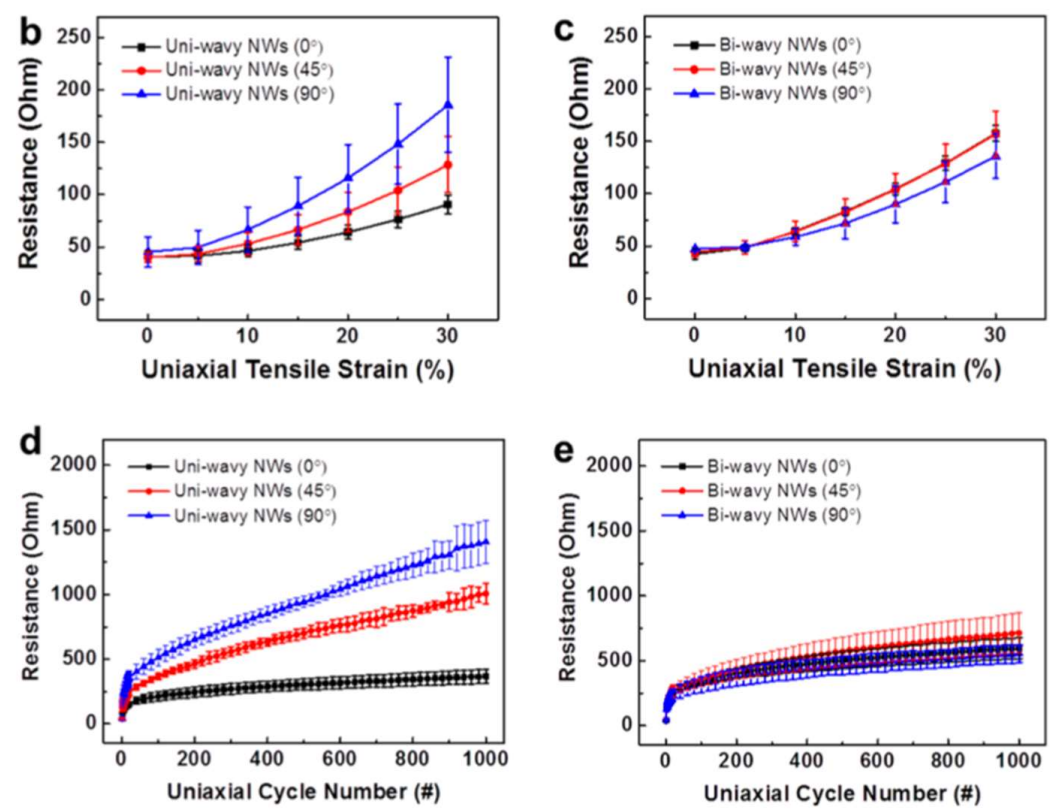

Figure 6. (a) Schematics showing the stretching directions of the uniaxial tensile strains for uniwavy NWs and biwavy NWs. Resistance changes as a function of the applied uniaxial tensile strain for (b) uniwavy NWs and (c) biwavy NWs. Resistance changes as a function of the uniaxial cyclic strain for (d) uniwavy NWs and (e) biwavy NWs. Electrodes were repeatedly stretched to $30 \%$ and released back to 0\%. Reprinted from [55], with permission from American Chemical Society, 2017. 
In addition to pre-processing the Ag nanowire films, one can also make more complex structures to enhance the performance. Kim and co-workers [44] patterned polyepoxy acrylate (PEA) islands on Ag nanowires deposited on PUA substrates (Figure 7). Using this approach, the stretchability increased significantly, and a 60\% strain was sustained for 500 cycles [44].

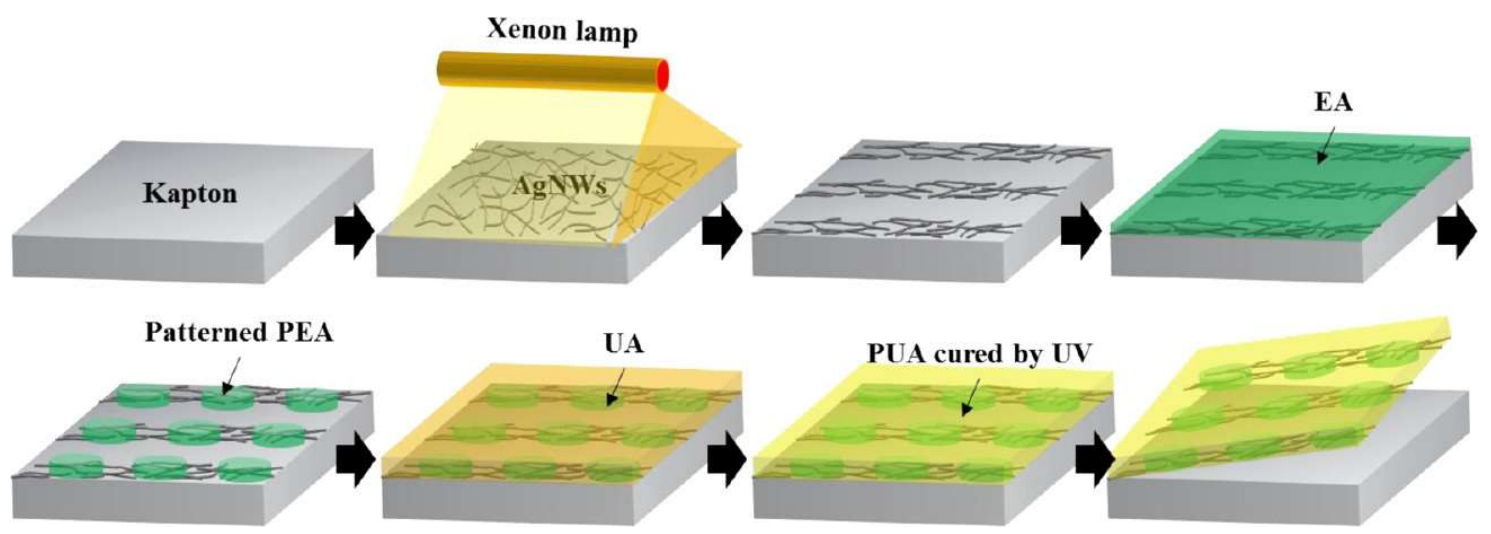

Figure 7. Scheme showing the fabrication of a heterogeneous Ag NW/polymer composite structure.

Reprinted from [44], with permission from American Chemical Society, 2017.

\subsection{Chemical Stability}

Since silver can react with oxygen and acids, an Ag nanowire-based TE is not chemically stable when it is exposed to air and acids. Additional procedures must be used to enhance the chemicalstability.

The most common way to protect Ag nanowires from chemical reactions is to encapsulate or polymerize the nanowires with a layer of inorganic or organic material. This layer prevents direct contact between the Ag nanowires and potential reactants.

Metal oxides are the most commonly used inorganic materials for the protection of Ag nanowires from oxidation. Atomic layer deposition (ALD) of $\mathrm{Al}_{2} \mathrm{O}_{3}$ onto $\mathrm{Ag}$ nanowires was found to effectively protect the nanowires from oxidation [5,60,61]. Alternatively, $\mathrm{ZnO}$ [48] and $\mathrm{TiO}_{2}$ [43] deposited by ALD were also shown to have the same protective effect. Despite their anti-oxidation effects, some of the metal oxide coatings, such as $\mathrm{ZnO}$ and $\mathrm{Al}_{2} \mathrm{O}_{3}$, are not chemically stable in acidic conditions, thereby limiting their application in certain environments.

Glass fabric materials have been used to enhance the chemical stability of Ag nanowire films. A film with a glass-fabric-reinforced transparent composite (GFRHybrimer) embedded with the Ag nanowire networks showed more resistance to corrosive reagents such as $5 \mathrm{wt} \% \mathrm{~K}_{2} \mathrm{~S}$ [62].

Polymers are alternative materials for protecting Ag nanowires through encapsulation [52] or polymerization [63,64]. An epoxy resin protection [65] could extend the lifetime of a silver nanowire TE to 40 days at $85^{\circ} \mathrm{C}$ and $85 \%$ relative humidity. In many cases, the polymers are added for other purposes such as enhancing the adhesion [66]. However, the protective effects are spontaneously added to the Ag nanowires.

Mayousse et al. [34] reported a special case where as synthesized silver nanowires are stable for 2.5 years under lab conditions and for 4 months at $38^{\circ} \mathrm{C}$ with $90 \%$ relative humidity. However, it is not clear if the nanowires were covered by polymers or organic molecules because the nanowires were synthesized in an organic solution containing polyvinvylprrolidone (PVP) and no washing steps were mentioned in their paper.

\subsection{Thermal Stability}

Thermal stability is required for the application of TEs in high temperature environments. The thermal stability of the polymer substrates is also crucial to TEs, but this issue is not considered in this review. Instead, this section focuses on the thermal stability of the Ag nanowire film. 
Ag nanowires are thermally stable at temperatures below $200{ }^{\circ} \mathrm{C}$, while higher temperatures lead to decomposition [67]. The most common phenomenon observed after heating Ag nanowires is that the nanowires shrink upon heating and form droplets. This phenomenon is also elsewhere called negative thermal expansion [68]. It is caused by the coalescence of Ag nanowires [69]. This coalescence is due to the high surface energy of the nanowires and is size [70] and temperature [69] dependent. Smaller nanostructures have higher surface energies [70] and are thus more likely to coalesce, while higher temperatures accelerate the coalescence process [71]. The result of the coalescence is that the nanowires break into small droplets. The origin of the droplet-forming behavior of heated nanowires is called Rayleigh-Plateau instability [14].

Surface coating with metal oxides is a common way to reduce Rayleigh-Plateau instability and thus enhance the thermal stability. An Ag nanowire film that was coated using the ALD method by $\mathrm{ZnO}$ with a thickness of $4.5 \mathrm{~nm}$ had long-term thermal stability up to $300{ }^{\circ} \mathrm{C}$ [60]. The stability could be improved up to $350{ }^{\circ} \mathrm{C}$ by coating with $40 \mathrm{~nm}$ thick $\mathrm{ZnO}$ [67]. Greater stability was also found for $\mathrm{Al}_{2} \mathrm{O}_{3}$-coated $\mathrm{Ag}$ nanowire films (Figure 8), where a $5.3 \mathrm{~nm}$ thick $\mathrm{Al}_{2} \mathrm{O}_{3}$ layer increased the stability to $380{ }^{\circ} \mathrm{C}$ [5]. $\mathrm{TiO}_{2}$ is another material that can be ALD coated on Ag nanowires to enhance the thermal stability [72].
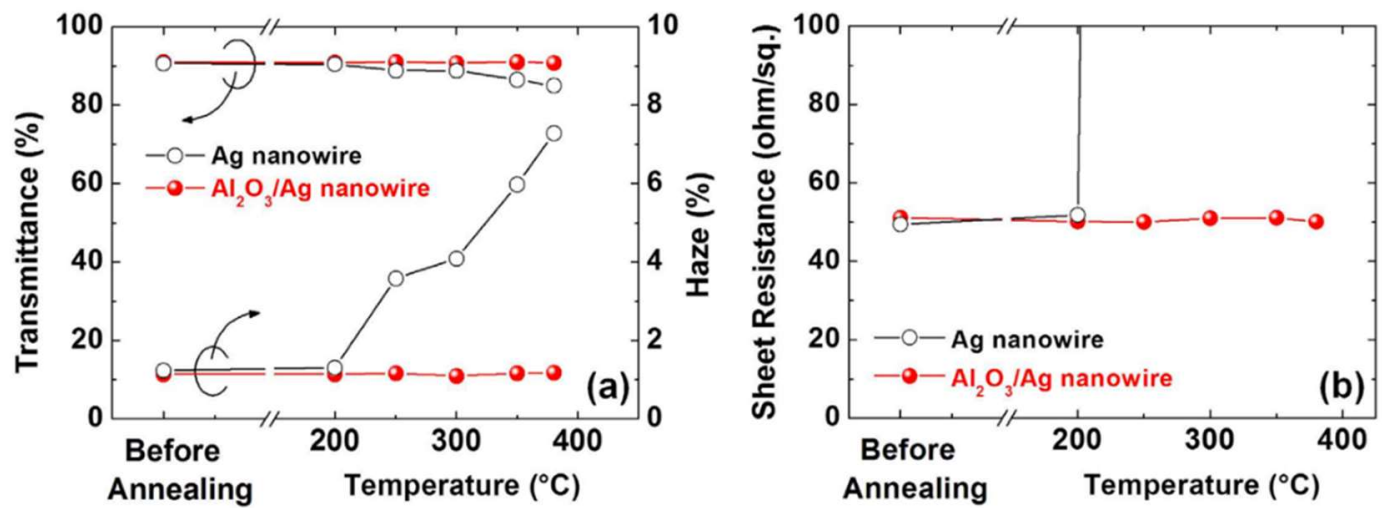

Figure 8. Changes in (a) optical transmittance/haze and (b) sheet resistance of the $\mathrm{Ag}$ and $\mathrm{Al}_{2} \mathrm{O}_{3} / \mathrm{Ag}$ nanowire electrodes as a function of the annealing temperature. The annealing time is $20 \mathrm{~min}$. Reprinted from [5], with permission from Springer Nature Limited, 2017.

\subsection{Tuning of the Optical Properties}

The total transparency of a TE includes both direct (called specular or clarity) and diffuse transmittance. Direct transmittance refers to the percentage of light that passes through the TE without being scattered. In other words, haze and specular transmittance are the percentage of light that are subject to wide and narrow scattering, respectively. Most studies of TEs focus on the transmittance and the haze. In some applications, high transmittances and low haze are desired, such as in touch panels [14], while in some applications, a high haze is desired, such as in solar cells [73].

The haze of Ag nanowire films depends on the diameter and length of the nanowires. For a single nanowire, the diameter determines the haze. However, for a nanowire film, the lengths of the nanowires are of great importance because the lengths determine the density of the film (also called the area fraction [74] of the nanowires). Therefore, the optical haze can be reduced by using longer and thinner nanowires [54].

Based on the above, it seems straightforward to make a TE with high transmittance and low haze by using thin nanowires [75]. However, TEs with thin nanowires have lower thermal and chemical stability compared to those with thick nanowires, thereby shortening their lifetime. This requires additional coatings. One route to obtain low haze TEs is to use ultra-long Ag nanowires with relatively thick diameters [76]. Another route to reduce the haze is to coat the Ag nanowires with materials that have smaller extinction coefficients (Figure 9), such as gold [77]. 
It also seems reasonable to consider making a high haze Ag TE using short and thick nanowires. The problem in this case is that it reduces the transmittance. In practice, researchers use extra coatings, such as FZO, on films made of thin nanowires to increase the optical haze [9].

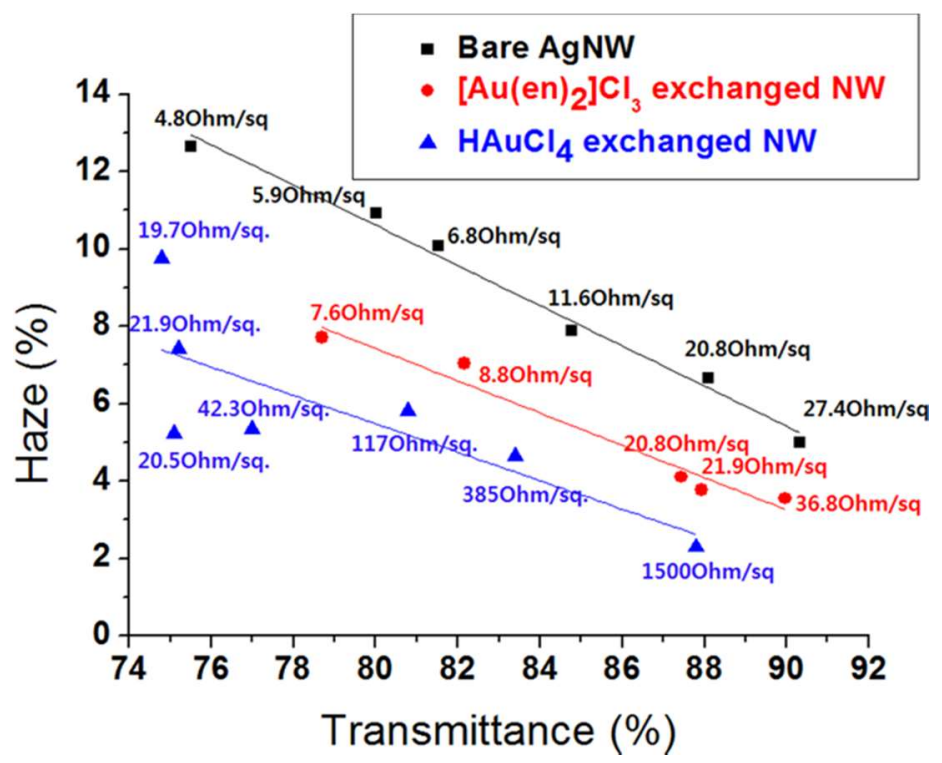

Figure 9. Comparison of haze and transmittance for transparent films fabricated with bare Ag nanowires, $\mathrm{Au}$-coated $\mathrm{Ag}$ nanowires made using $\mathrm{HAuCl}_{4}$ exchange, and $\mathrm{Au}$-coated $\mathrm{Ag}$ nanowires made using $\left[\mathrm{Au}(\mathrm{en})_{2}\right] \mathrm{Cl}_{3}$ exchange and $\mathrm{NH}_{3}$ treatment. The sheet resistance for each sample is also stated. Reprinted from [77], with permission from American Chemical Society, 2014.

\section{Conclusion and Future Perspectives}

Silver nanowire-based transparent electrodes (TEs) are promising candidates for replacing transparent conductive oxide (TCO) electrodes. Many studies have shown their excellent mechanical, electrical, optical, and chemical properties, enabling new applications that are not achievable using TCO electrodes. Many protocols have been developed for fabricating Ag nanowire-based TEs with the aim of industrial production.

It is generally recognized that the requirements of industrial production are a transmittance > $90 \%$ and a sheet resistance $<100 \Omega /$ sq. Recent advances in making silver nanowire-based TEs have indicated that such requirement could be accomplished easily.

Besides the above-mentioned requirements, there are more factors (Figure 10) to consider than just the requirement of industrial production.

(1) The flexibility of the TEs is becoming increasingly important due to the fast growth of flexible electronics. It is also of great importance for applications of TEs in bio-electronics such as electronic skin. A further requirement of the TEs for biological or biomedical application is the stretchability. Efforts have been made to address this issue, while more studies are needed.

(2) The chemical stability of silver is better than other metals such as copper or nickel that have been used for making TEs. However, TEs made by silver are still sensitive when exposed to air. The current protocol is to cover the silver nanowires with a layer of other materials that can stabilize the TEs. However, deposition of an extra layer such as $\mathrm{ZnO}$ usually requires a vacuum process that will limit the production and increase the cost. Improved solutions are expected to solve this problem.

(3) The thermal stability of silver nanowire based TEs has been studied intensively and the results show that the TEs can survive at temperatures higher than $300{ }^{\circ} \mathrm{C}$. Such stability is quite good and can be used in most of the applications. 
(4) High transmission of silver nanowire based TEs is aimed for in most of the studies, while few studies focus on the haze property. In most of the applications, high transmission is needed such as display. However, haze is of great importance in applications such as solar cells. There is, on the other hand a lack of methods to tune the transmission and the haze easily to fulfill different requirements.

(5) The conductivity of the silver nanowire based TEs is not a problem as shown by the studies. However, the electrical stability of the TEs has attracted more and more attention because the conductivity of the TEs could reduce over time. Electromigration and Joule heating are the two main reasons. Deposition of an extra layer such as a thin $\mathrm{ZnO}$ film could delay the failure although better solutions are expected. Joule heating could be reduced by welding the nanowires to decrease junctions, while simpler methods need to be developed to increase the procedure and reduce the costs.

Recent advances of silver nanowire based TEs have shown their great potential in many applications. This also inspires the future development of small, flexible, and biocompatible electronics that are of great importance for biomedical applications, as well as network communications such as the internet of things (IoT).

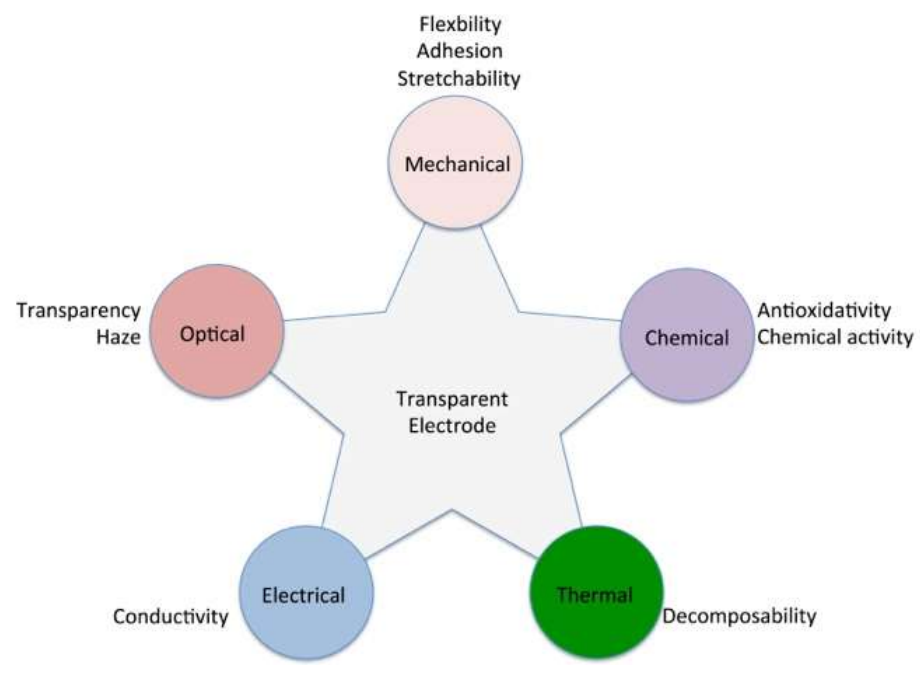

Figure 10. Schematic drawing of the basic factors for evaluating transparent electrodes.

Author Contributions: Writing-Original Draft Preparation, R.Z. and M.E.

Funding: This research was funded the Knowledge Foundation, the Swedish Energy Agency, the EU Regional Funds and the County Administrative Board in Västernorrland, Sweden.

Conflicts of Interest: The authors declare no conflicts of interest.

\section{References}

1. Kou, P.; Yang, L.; Chang, C.; He, S. Improved Flexible Transparent Conductive Electrodes based on Silver Nanowire Networks by a Simple Sunlight Illumination Approach. Sci. Rep. 2017, 7, 42052. [CrossRef] [PubMed]

2. Chu, H.C.; Chang, Y.C.; Lin, Y.; Chang, S.H.; Chang, W.C.; Li, G.A.; Tuan, H.Y. Spray-Deposited Large-Area Copper Nanowire Transparent Conductive Electrodes and Their Uses for Touch Screen Applications. ACS Appl. Mater. Interfaces 2016, 8, 13009-13017. [CrossRef] [PubMed]

3. Kim, T.; Canlier, A.; Kim, G.H.; Choi, J.; Park, M.; Han, S.M. Electrostatic spray deposition of highly transparent silver nanowire electrode on flexible substrate. ACS Appl. Mater. Interfaces 2013, 5, 788-794. [CrossRef] [PubMed] 
4. Hwang, B.; Shin, H.A.S.; Kim, T.; Joo, Y.C.; Han, S.M. Highly reliable Ag nanowire flexible transparent electrode with mechanically welded junctions. Small 2014, 10, 3397-3404. [CrossRef] [PubMed]

5. Hwang, B.; An, Y.; Lee, H.; Lee, E.; Becker, S.; Kim, Y.-H.; Kim, H. Highly Flexible and Transparent Ag Nanowire Electrode Encapsulated with Ultra-Thin $\mathrm{Al}_{2} \mathrm{O}_{3}$ : Thermal, Ambient, and Mechanical Stabilities. Sci. Rep. 2017, 7, 41336. [CrossRef] [PubMed]

6. Hsu, P.C.; Kong, D.; Wang, S.; Wang, H.; Welch, A.J.; Wu, H.; Cui, Y. Electrolessly deposited electrospun metal nanowire transparent electrodes. J. Am. Chem. Soc. 2014, 136, 10593-10596. [CrossRef] [PubMed]

7. Wang, X.; Wang, R.; Shi, L.; Sun, J. Synthesis of Metal/Bimetal Nanowires and Their Applications as Flexible Transparent Electrodes. Small 2015, 11, 4737-4744. [CrossRef] [PubMed]

8. Ye, T.; Jun, L.; Kun, L.; Hu, W.; Ping, C.; Ya-Hui, D.; Zheng, C.; Yun-Fei, L.; Hao-Ran, W.; Yu, D. Inkjet-printed Ag grid combined with Ag nanowires to form a transparent hybrid electrode for organic electronics. Org. Electron. 2017, 41, 179-185. [CrossRef]

9. Han, J.; Yuan, S.; Liu, L.; Qiu, X.; Gong, H.; Yang, X.; Li, C.; Hao, Y.; Cao, B. Fully indium-free flexible Ag nanowires/ZnO:F composite transparent conductive electrodes with high haze. J. Mater. Chem. A 2015, 3, 5375-5384. [CrossRef]

10. Sannicolo, T.; Lagrange, M.; Cabos, A.; Celle, C.; Simonato, J.P.; Bellet, D. Metallic Nanowire-Based Transparent Electrodes for Next Generation Flexible Devices: a Review. Small 2016, 12, 6052-6075. [CrossRef] [PubMed]

11. Xue, J.; Song, J.; Dong, Y.; Xu, L.; Li, J.; Zeng, H. Nanowire-based transparent conductors for flexible electronics and optoelectronics. Sci. Bull. 2017, 62, 143-156. [CrossRef]

12. De, S.; King, P.J.; Lyons, P.E.; Khan, U.; Coleman, J.N. Size Effects and the Problem with Percolation in Nanostructured Transparent Conductors. ACS Nano 2010, 4, 7064-7072. [CrossRef] [PubMed]

13. De, S.; Coleman, J.N. The effects of percolation in nanostructured transparent conductors. MRS Bull. 2011, 36, 774-781. [CrossRef]

14. Lagrange, M.; Langley, D.P.; Giusti, G.; Jiménez, C.; Bréchet, Y.; Bellet, D. Optimization of silver nanowire-based transparent electrodes: effects of density, size and thermal annealing. Nanoscale 2015, 7, 17410-17423. [CrossRef] [PubMed]

15. Aharony, A.; Stauffer, D. Introduction to percolation theory; Taylor \& Francis: London, UK, 1991.

16. Hu, L.; Hecht, D.S.; Grüner, G. Carbon Nanotube Thin Films: Fabrication, Properties, and Applications. Chem. Rev. 2010, 110, 5790-5844. [CrossRef] [PubMed]

17. Hu, L.; Hecht, D.S.; Grüner, G. Percolation in Transparent and Conducting Carbon Nanotube Networks. Nano Lett. 2004, 4, 2513-2517. [CrossRef]

18. Mutiso, R.M.; Sherrott, M.C.; Rathmell, A.R.; Wiley, B.J.; Winey, K.I. Integrating Simulations and Experiments To Predict Sheet Resistance and Optical Transmittance in Nanowire Films for Transparent Conductors. ACS Nano 2013, 7, 7654-7663. [CrossRef] [PubMed]

19. Khanarian, G.; Joo, J.; Liu, X.-Q.; Eastman, P.; Werner, D.; O'Connell, K.; Trefonas, P. The optical and electrical properties of silver nanowire mesh films. J. Appl. Phys. 2013, 114, 024302. [CrossRef]

20. Van de Hulst, H.C. Light Scattering by Small Particles; Dover Publications, Inc.: New York, NY, USA, 1957; ISBN 0-486-64228-3.

21. Meeten, G.H. Transparency, translucency and gloss. In Optical Properties Of Polymers; Elsevier: London, UK, 1986.

22. Preston, C.; Xu, Y.; Han, X.; Munday, J.N.; Hu, L. Optical haze of transparent and conductive silver nanowire films. Nano Res. 2013, 6, 461-468. [CrossRef]

23. Deignan, G.; Goldthorpe, I.A. The dependence of silver nanowire stability on network composition and processing parameters. RSC Adv. 2017, 7, 35590-35597. [CrossRef]

24. Zhao, J.; Sun, H.; Dai, S.; Wang, Y.; Zhu, J. Electrical Breakdown of Nanowires. Nano Lett. 2011, 11, 4647-4651. [CrossRef] [PubMed]

25. Khaligh, H.H.; Goldthorpe, I.A. Failure of silver nanowire transparent electrodes under current flow. Nanoscale Res. Lett. 2013, 8, 235. [CrossRef] [PubMed]

26. Khan, A.; Nguyen, V.H.; Muñoz-Rojas, D.; Aghazadehchors, S.; Jiménez, C.; Nguyen, N.D.; Bellet, D. Stability Enhancement of Silver Nanowire Networks with Conformal ZnO Coatings Deposited by Atmospheric Pressure Spatial Atomic Layer Deposition. ACS Appl. Mater. Interfaces 2018, 10, 19208-19217. [CrossRef] [PubMed] 
27. Chen, D.; Zhao, F.; Tong, K.; Saldanha, G.; Liu, C.; Pei, Q. Mitigation of Electrical Failure of Silver Nanowires under Current Flow and the Application for Long Lifetime Organic Light-Emitting Diodes. Adv. Electron. Mater. 2016, 2, 1600167. [CrossRef]

28. Sannicolo, T.; Muñoz-Rojas, D.; Nguyen, N.D.; Moreau, S.; Celle, C.; Simonato, J.-P.; Bréchet, Y.; Bellet, D. Direct Imaging of the Onset of Electrical Conduction in Silver Nanowire Networks by Infrared Thermography: Evidence of Geometrical Quantized Percolation. Nano Lett. 2016, 16, 7046-7053. [CrossRef] [PubMed]

29. Rayleigh, L. On The Instability Of Jets. Proc. London Math. Soc. 1878, 1, 4-13. [CrossRef]

30. Hummelgård, M.; Zhang, R.Y.; Nilsson, H.-E.; Olin, H. Electrical sintering of silver nanoparticle ink studied by in-situ TEM probing. PLoS ONE 2011, 6, e17209. [CrossRef] [PubMed]

31. Lu, H.; Zhang, D.; Cheng, J.; Liu, J.; Mao, J.; Choy, W.C.H. Locally Welded Silver Nano-Network Transparent Electrodes with High Operational Stability by a Simple Alcohol-Based Chemical Approach. Adv. Funct. Mater. 2015, 25, 4211-4218. [CrossRef]

32. Song, T.-B.; Chen, Y.; Chung, C.-H.; Yang, Y.M.; Bob, B.; Duan, H.-S.; Li, G.; Tu, K.-N.; Huang, Y.; Yang, Y. Nanoscale Joule Heating and Electromigration Enhanced Ripening of Silver Nanowire Contacts. ACS Nano 2014, 8, 2804-2811. [CrossRef] [PubMed]

33. Spechler, J.A.; Nagamatsu, K.A.; Sturm, J.C.; Arnold, C.B. Improved Efficiency of Hybrid Organic Photovoltaics by Pulsed Laser Sintering of Silver Nanowire Network Transparent Electrode. ACS Appl. Mater. Interfaces 2015, 7, 10556-10562. [CrossRef] [PubMed]

34. Mayousse, C.; Celle, C.; Fraczkiewicz, A.; Simonato, J.-P. Stability of silver nanowire based electrodes under environmental and electrical stresses. Nanoscale 2015, 7, 2107-2115. [CrossRef] [PubMed]

35. Li, R.-Z.; Hu, A.; Zhang, T.; Oakes, K.D. Direct Writing on Paper of Foldable Capacitive Touch Pads with Silver Nanowire Inks. ACS Appl. Mater. Interfaces 2014, 6, 21721-21729. [CrossRef] [PubMed]

36. Park, J.H.; Hwang, G.-T.; Kim, S.; Seo, J.; Park, H.-J.; Yu, K.; Kim, T.-S.; Lee, K.J. Flash-Induced Self-Limited Plasmonic Welding of Silver Nanowire Network for Transparent Flexible Energy Harvester. Adv. Mater. 2017, 29, 1603473. [CrossRef] [PubMed]

37. Garnett, E.C.; Cai, W.; Cha, J.J.; Mahmood, F.; Connor, S.T.; Greyson Christoforo, M.; Cui, Y.; McGehee, M.D.; Brongersma, M.L. Self-limited plasmonic welding of silver nanowire junctions. Nat. Mater. 2012, 11, 241-249. [CrossRef] [PubMed]

38. Zhu, S.; Gao, Y.; Hu, B.; Li, J.; Su, J.; Fan, Z.; Zhou, J. Transferable self-welding silver nanowire network as high performance transparent flexible electrode. Nanotechnology 2013, 24, 335202. [CrossRef] [PubMed]

39. Cheong, H.-G.; Triambulo, R.E.; Lee, G.-H.; Yi, I.-S.; Park, J.-W. Silver Nanowire Network Transparent Electrodes with Highly Enhanced Flexibility by Welding for Application in Flexible Organic Light-Emitting Diodes. ACS Appl. Mater. Interfaces 2014, 6, 7846-7855. [CrossRef] [PubMed]

40. Liu, Y.; Zhang, J.; Gao, H.; Wang, Y.; Liu, Q.; Huang, S.; Guo, C.F.; Ren, Z. Capillary-Force-Induced Cold Welding in Silver-Nanowire-Based Flexible Transparent Electrodes. Nano Lett. 2017, 17, 1090-1096. [CrossRef] [PubMed]

41. Xia, Y.; Xiong, Y.; Lim, B.; Skrabalak, S.E. Shape-controlled synthesis of metal nanocrystals: Simple chemistry meets complex physics? Angew. Chem. Int. Ed. 2009, 48, 60-103. [CrossRef] [PubMed]

42. Xiong, W.; Liu, H.; Chen, Y.; Zheng, M.; Zhao, Y.; Kong, X.; Wang, Y.; Zhang, X.; Kong, X.; Wang, P.; Jiang, L. Highly Conductive, Air-Stable Silver Nanowire@Iongel Composite Films toward Flexible Transparent Electrodes. Adv. Mater. 2016, 28, 7167-7172. [CrossRef] [PubMed]

43. Lee, D.G.; Lee, D.; Yoo, J.S.; Lee, S.; Jung, H.S. Effective passivation of Ag nanowire-based flexible transparent conducting electrode by $\mathrm{TiO}_{2}$ nanoshell. Nano Converg. 2016, 3, 20. [CrossRef] [PubMed]

44. Kim, Y.; Jun, S.; Ju, B.-K.; Kim, J.-W. Heterogeneous Configuration of a Ag Nanowire/Polymer Composite Structure for Selectively Stretchable Transparent Electrodes. ACS Appl. Mater. Interfaces 2017, 9, 7505-7514. [CrossRef] [PubMed]

45. Kim, D.H.; Yu, K.C.; Kim, Y.; Kim, J.W. Highly Stretchable and Mechanically Stable Transparent Electrode Based on Composite of Silver Nanowires and Polyurethane-Urea. ACS Appl. Mater. Interfaces 2015, 7, 15214-15222. [CrossRef] [PubMed]

46. Madaria, A.R.; Kumar, A.; Ishikawa, F.N.; Zhou, C. Uniform, Highly Conductive, and Patterned Transparent Films of a Percolating Silver Nanowire Network on Rigid and Flexible Substrates Using a Dry Transfer Technique. Nano Res 2010, 3, 564-573. [CrossRef] 
47. Kim, A.; Won, Y.; Woo, K.; Kim, C.H.; Moon, J. Highly transparent low resistance ZnO/Ag nanowire/ZnO composite electrode for thin film solar cells. ACS Nano 2013, 7, 1081-1091. [CrossRef] [PubMed]

48. Göbelt, M.; Keding, R.; Schmitt, S.W.; Hoffmann, B.; Jäckle, S.; Latzel, M.; Radmilović, V.V.; Radmilović, V.R.; Spiecker, E.; Christiansen, S. Encapsulation of silver nanowire networks by atomic layer deposition for indium-free transparent electrodes. Nano Energy 2015, 16, 196-206. [CrossRef]

49. Song, T.B.; Rim, Y.S.; Liu, F.; Bob, B.; Ye, S.; Hsieh, Y.T.; Yang, Y. Highly Robust Silver Nanowire Network for Transparent Electrode. ACS Appl. Mater. Interfaces 2015, 7, 24601-24607. [CrossRef] [PubMed]

50. Wu, C.; Kim, T.W.; Li, F.; Guo, T. Wearable Electricity Generators Fabricated Utilizing Transparent Electronic Textiles Based on Polyester/Ag Nanowires/Graphene Core-Shell Nanocomposites. ACS Nano 2016, 10, 6449-6457. [CrossRef] [PubMed]

51. Nam, S.; Song, M.; Kim, D.-H.; Cho, B.; Lee, H.M.; Kwon, J.-D.; Park, S.-G.; Nam, K.-S.; Jeong, Y.; Kwon, S.-H.; et al. Ultrasmooth, extremely deformable and shape recoverable Ag nanowire embedded transparent electrode. Sci. Rep. 2014, 4, 4788. [CrossRef] [PubMed]

52. Jin, Y.; Wang, K.; Cheng, Y.; Pei, Q.; Xu, Y.; Xiao, F. Removable Large-Area Ultrasmooth Silver Nanowire Transparent Composite Electrode. ACS Appl. Mater. Interfaces 2017, 9, 4733-4741. [CrossRef] [PubMed]

53. Lian, L.; Dong, D.; Yang, S.; Wei, B.; He, G. Highly Conductive and Uniform Alginate/Silver Nanowire Composite Transparent Electrode by Room Temperature Solution Processing for Organic Light Emitting Diode. ACS Appl. Mater. Interfaces 2017, 9, 11811-11818. [CrossRef] [PubMed]

54. He, X.; He, R.; Liu, A.; Chen, X.; Zhao, Z.; Feng, S.; Chen, N.; Zhang, M. A highly conductive, flexible, transparent composite electrode based on the lamination of silver nanowires and polyvinyl alcohol. J. Mater. Chem. C 2014, 2, 9737-9745. [CrossRef]

55. Kim, B.S.; Pyo, J.B.; Son, J.G.; Zi, G.; Lee, S.-S.; Park, J.H.; Lee, J. Biaxial Stretchability and Transparency of Ag Nanowire 2D Mass-Spring Networks Prepared by Floating Compression. ACS Appl. Mater. Interfaces 2017, 9, 10865-10873. [CrossRef] [PubMed]

56. Kim, K.K.; Hong, S.; Cho, H.M.; Lee, J.; Suh, Y.D.; Ham, J.; Ko, S.H. Highly Sensitive and Stretchable Multidimensional Strain Sensor with Prestrained Anisotropic Metal Nanowire Percolation Networks. Nano Lett. 2015, 15, 5240-5247. [CrossRef] [PubMed]

57. Lee, C.-J.; Park, K.H.; Han, C.J.; Oh, M.S.; You, B.; Kim, Y.-S.; Kim, J.-W. Crack-induced Ag nanowire networks for transparent, stretchable, and highly sensitive strain sensors. Sci. Rep. 2017, 7, 7959. [CrossRef] [PubMed]

58. You, B.; Kim, Y.; Ju, B.-K.; Kim, J.-W. Highly Stretchable and Waterproof Electroluminescence Device Based on Superstable Stretchable Transparent Electrode. ACS Appl. Mater. Interfaces 2017, 9, 5486-5494. [CrossRef] [PubMed]

59. Liang, J.; Li, L.; Niu, X.; Yu, Z.; Pei, Q. Elastomeric polymer light-emitting devices and displays. Nat. Photonics 2013, 7, 817-824. [CrossRef]

60. Chen, D.; Liang, J.; Liu, C.; Saldanha, G.; Zhao, F.; Tong, K.; Liu, J.; Pei, Q. Thermally Stable Silver Nanowire-Polyimide Transparent Electrode Based on Atomic Layer Deposition of Zinc Oxide on Silver Nanowires. Adv. Funct. Mater. 2015, 25, 7512-7520. [CrossRef]

61. Bellet, D.; Lagrange, M.; Sannicolo, T.; Aghazadehchors, S.; Nguyen, V.H.; Langley, D.P.; Muñoz-Rojas, D.; Jiménez, C.; Bréchet, Y.; Nguyen, N.D. Transparent Electrodes Based on Silver Nanowire Networks: From Physical Considerations towards Device Integration. Materials 2017, 10, 570. [CrossRef] [PubMed]

62. Im, H.-G.; Jin, J.; Ko, J.-H.; Lee, J.; Lee, J.-Y.; Bae, B.-S. Flexible transparent conducting composite films using a monolithically embedded AgNW electrode with robust performance stability. Nanoscale 2014, 6, 711-715. [CrossRef] [PubMed]

63. Yu, Z.; Zhang, Q.; Li, L.; Chen, Q.; Niu, X.; Liu, J.; Pei, Q. Highly Flexible Silver Nanowire Electrodes for Shape-Memory Polymer Light-Emitting Diodes. Adv. Mater. 2011, 23, 664-668. [CrossRef] [PubMed]

64. Yang, Y.; Ding, S.; Araki, T.; Jiu, J.; Sugahara, T.; Wang, J.; Vanfleteren, J.; Sekitani, T.; Suganuma, K. Facile fabrication of stretchable Ag nanowire/polyurethane electrodes using high intensity pulsed light. Nano Res. 2016, 9, 401-414. [CrossRef]

65. Jiu, J.; Wang, J.; Sugahara, T.; Nagao, S.; Nogi, M.; Koga, H.; Suganuma, K.; Hara, M.; Nakazawa, E.; Uchida, H. The effect of light and humidity on the stability of silver nanowire transparent electrodes. RSC Adv. 2015, 5, 27657-27664. [CrossRef] 
66. Wang, J.; Jiu, J.; Sugahara, T.; Nagao, S.; Nogi, M.; Koga, H.; He, P.; Suganuma, K.; Uchida, H. Highly Reliable Silver Nanowire Transparent Electrode Employing Selectively Patterned Barrier Shaped by Self-Masked Photolithography. ACS Appl. Mater. Interfaces 2015, 7, 23297-23304. [CrossRef] [PubMed]

67. Singh, M.; Rana, T.R.; Kim, S.; Kim, K.; Yun, J.H.; Kim, J. Silver Nanowires Binding with Sputtered ZnO to Fabricate Highly Conductive and Thermally Stable Transparent Electrode for Solar Cell Applications. ACS Appl. Mater. Interfaces 2016, 8, 12764-12771. [CrossRef] [PubMed]

68. Ho, D.T.; Kwon, S.-Y.; Park, H.S.; Kim, S.Y. Negative Thermal Expansion of Ultrathin Metal Nanowires: A Computational Study. Nano Lett. 2017, 17, 5113-5118. [CrossRef] [PubMed]

69. Moon, K.-S.; Dong, H.; Maric, R.; Pothukuchi, S.; Hunt, A.; Li, Y.; Wong, C.P. Thermal Behavior of Silver Nanoparticles for Low-Temperature Interconnect Applications. J. Electron. Mater. 2005, 34, 168-175. [CrossRef]

70. Nanda, K.K.; Maisels, A.; Kruis, F.E.; Fissan, H.; Stappert, S. Higher Surface Energy of Free Nanoparticles. Phys. Rev. Lett. 2003, 91, 106102. [CrossRef] [PubMed]

71. Zhang, R.; Hummelgård, M.; Olin, H. Single layer porous gold films grown at different temperatures. Phys. $B$ Condens. Matter 2010, 405, 4517-4522. [CrossRef]

72. Yeh, M.-H.; Chen, P.-H.; Yang, Y.-C.; Chen, G.-H.; Chen, H.-S. Investigation of Ag-TiO 2 Interfacial Reaction of Highly Stable Ag Nanowire Transparent Conductive Film with Conformal $\mathrm{TiO}_{2}$ Coating by Atomic Layer Deposition. ACS Appl. Mater. Interfaces 2017, 9, 10788-10797. [CrossRef] [PubMed]

73. Fang, Z.; Zhu, H.; Yuan, Y.; Ha, D.; Zhu, S.; Preston, C.; Chen, Q.; Li, Y.; Han, X.; Lee, S.; et al. Novel Nanostructured Paper with Ultrahigh Transparency and Ultrahigh Haze for Solar Cells. Nano Lett. 2014, 14, 765-773. [CrossRef] [PubMed]

74. Ye, S.; Rathmell, A.R.; Chen, Z.; Stewart, I.E.; Wiley, B.J. Metal Nanowire Networks: The Next Generation of Transparent Conductors. Adv. Mater. 2014, 26, 6670-6687. [CrossRef] [PubMed]

75. Menamparambath, M.M.; Yang, K.; Kim, H.H.; Bae, O.S.; Jeong, M.S.; Choi, J.-Y.; Baik, S. Reduced haze of transparent conductive films by smaller diameter silver nanowires. Nanotechnology 2016, 27, 465706. [CrossRef] [PubMed]

76. Araki, T.; Jiu, J.; Nogi, M.; Koga, H.; Nagao, S.; Sugahara, T.; Suganuma, K. Low haze transparent electrodes and highly conducting air dried films with ultra-long silver nanowires synthesized by one-step polyol method. Nano Res. 2014, 7, 236-245. [CrossRef]

77. Kim, T.; Canlier, A.; Cho, C.; Rozyyev, V.; Lee, J.Y.; Han, S.M. Highly transparent Au-coated ag nanowire transparent electrode with reduction in haze. ACS Appl. Mater. Interfaces 2014, 6, 13527-13534. [CrossRef] [PubMed]

(C) 2018 by the authors. Licensee MDPI, Basel, Switzerland. This article is an open access article distributed under the terms and conditions of the Creative Commons Attribution (CC BY) license (http://creativecommons.org/licenses/by/4.0/). 